\title{
9 \\ Stormwater Management and Implementation of BMPs at Miami International Airport
}

\author{
Michael F. Schmidt, Nancy B. Pantoja and Luis Lopez-Blazquez
}

Miami-Dade Aviation Department (MDAD) began a US\$5.4 billion capital improvement program (CIP) at Miami International Airport (MIA) in 1990. A key element in the planning and environmental permitting is the Stormwater Master Plan (SWMP, CDM 1992) for the 5 square mile airport in urban Miami. The SWMP included comprehensive evaluations of hydrology, hydraulics, water quality, best management practices (BMPs), and facility planning in phases to allow cost-effective implementation of the CIP while aircraft operations continued and increased to serve growing air traffic demands.

A variety of constraints were identified including the protection of aircraft passenger safety (no fog or bird attractants) and the environment (flood control, water quality protection and improvement, manatee access, and hazardous material cleanups at more than twenty locations). Aircraft passenger safety issues regulated by the Federal Aviation Administration had to be balanced versus the environmental permitting requirements of the United States Environmental Protection Agency, United States Army Corps of Engineers, Florida Department of Environmental Protection, South Florida Water Management District, and Miami-Dade Department of Environmental Resource Management.

MDAD has proactively implemented a BMP Treatment Train, which includes a series of activities to reduce nonpoint source pollutant load generation and to remove pollutants from the runoff prior to discharge. The BMP

Schmidt, M.F., N.B. Pantoja and L. Lopez-Blazquez. 2004. "Stormwater Management and Implementation of BMPs at Miami International Airport." Journal of Water Management Modeling R220-09. doi: 10.14796/JWMM.R220-09.

(C) CHI 2004 www.chijournal.org ISSN: 2292-6062 (Formerly in Innovative Modeling of

Urban Water Systems. ISBN: 0-9683681-9-0) 
Treatment Train has been shown by water quality monitoring to cost-effectively treat runoff from the airport to meet federal, state, and local standards and permit requirements. Implementation has been coordinated with the CIP to allow timely and appropriate retrofits to the system. This chapter presents an overview of the MIA Stormwater Management Program and a summary of the successful implementation of the BMP Treatment Train.

\subsection{Background}

MDAD began a US\$5.4 billion CIP at MIA in 1990. A key element in the planning and environmental permitting is the SWMP for the 5 square mile (13 $\mathrm{km}^{2}$ ) airport in urban Miami. The airport has five outfalls that discharge to two systems: the Tamiami Canal (also called the C-6 Canal) and the Ludlam Canal, which flows north to the Miami River (Figure 9.1). Both are regulated systems with major South Florida Water Management District (SFWMD) water control structures downstream.

The SWMP included comprehensive evaluations of hydrology, hydraulics, water quality, BMPs, and facility planning in phases to allow cost-effective implementation of the CIP while aircraft operations continued and increased to

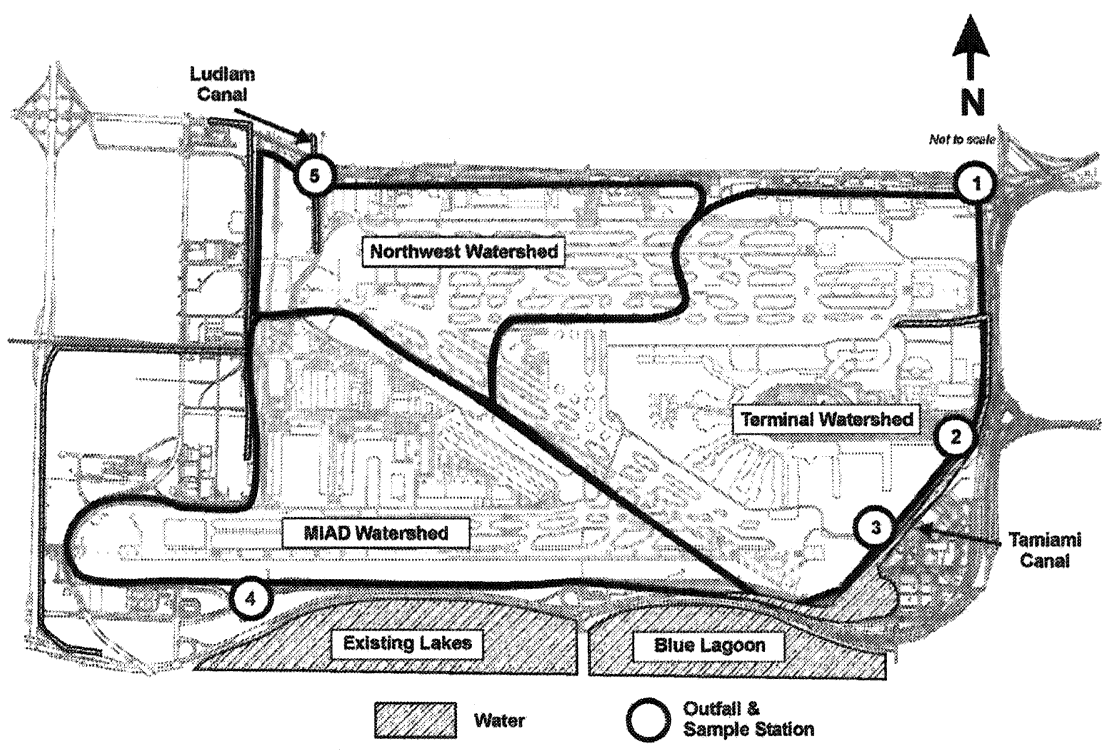

Figure 9.1 Miami International Airport watersheds and outfall locations. 
serve growing air traffic demands. A variety of planning constraints were identified including the protection of aircraft passenger safety (no fog or bird attractants) and the environment (flood control, water quality protection and improvement, manatee access, and hazardous material cleanups from more than twenty underground sources).

Aircraft passenger safety issues regulated by the Federal Aviation Administration (FAA) had to be balanced versus the environmental permitting requirements of the United States Environmental Protection Agency (USEPA), United States Army Corps of Engineers (USACE), Florida Department of Environmental Protection (FDEP), South Florida Water Management District (SFWMD), and Miami-Dade Department of Environmental Resource Management (DERM).

Accordingly, Levels of Service (LOSs) were identified for flood control, water quality, and aircraft passenger safety based on the following:

- FAA Criteria for Aircraft Passenger Safety(Limit airside ponding, avoid creating new pond locations),

- MDAD landside flood control LOS (protect against building and major road flooding) and allow some short duration shallow ponding during extreme events (e.g. greater then $10 \mathrm{in} .(254 \mathrm{~mm})$ of rainfall over $72 \mathrm{~h}$ ),

- SFWMD peak flow limitations (site at or below permitted levels), and

- SFWMD runoff treatment to meet water quality standards at the five outfalls.

CDM then systematically developed the SWMP for the airport's watersheds to meet the environmental permitting requirements and associated LOSs. This included both water quantity (flood control) and water quality (runoff treatment) components.

Historically, the grassed swales in the infield areas have provided shallow, short duration retention, which is consistent with both FAA and SFWMD requirements. This provides treatment of nearly half of the airport area; however, the remaining half of the airport also needed runoff treatment as part of the redevelopment efforts. The conventional BMPs of retention and detention require ponding of water to treat and attenuate runoff and can be a bird and/or fog attractant; therefore, an innovative approach needed to be developed to balance the competing regulatory requirements. The project team developed a BMP Treatment Train based on the FDEP approach (FDEP 1986) to provide necessary retrofit treatment and attenuation of stormwater runoff. The 
modifications focused on incorporating the USEPA National Pollutant Discharge Elimination System (NPDES), FAA, and SFWMD requirements into one integrated system.

\subsection{BMP Treatment Train}

The BMP Treatment Train (Figure 9.2) consists of structural and nonstructural BMPs as well as construction and monitoring activities. These activities were designed to minimize the potential for pollution by controlling the generation of pollutants in stormwater runoff and by controlling pollutants as close to potential sources as possible. The non-structural series of activities consists of a series of source controls such as sweeping and scrubbing paved areas, periodic maintenance, training and education in "housekeeping" and materials storage away from rainfall and stormwater runoff, environmental compliance in materials disposal, and spill prevention practices. Once runoff is generated, a series of first flush inlets divert the small event flows offline to a grit chamber (baffle box or equivalent) and coalescent plate oil-water separator. After treatment, the flow is recombined with the primary stormwater management system (PSMS) for discharge.

The first flush systems have peripheral troughs that were sized to collect the small flows up to a rainfall intensity based on long term rainfall records (44 years) and continuous simulation using the USACE Stormwater Treatment, Overflow, Runoff Model (STORM). Simulations for the first flush inlets included various storage versus flow rate options in order to determine the optimal device size based on the "knee of the curve". From these evaluations a peak intensity of $0.25 \mathrm{in} .(6.4 \mathrm{~mm}) / \mathrm{h}$ for up to $3 \mathrm{~h}$ became the basis for the first flush volume capture to the offline systems $(0.75 \mathrm{in} . / 19 \mathrm{~mm})$. This equates to approximately a $70 \%$ average annual rainfall volume capture (Figure 9.3). The remainder of treatment is provided in the PSMS prior to the outfalls.

The PSMS flood control infrastructure was sized and evaluated using the USEPA Stormwater Management Model (SWMM) RUNOFF module for hydrology and EXTRAN module for hydraulics. The dynamic flood routing in EXTRAN considered the extensive in-pipe storage in the MIA PSMS. The SWMM representations for the airport PSMS were calibrated to high water marks and recorded stages for historic storms ranging from 10 to $25 \mathrm{y}$ in return period. 


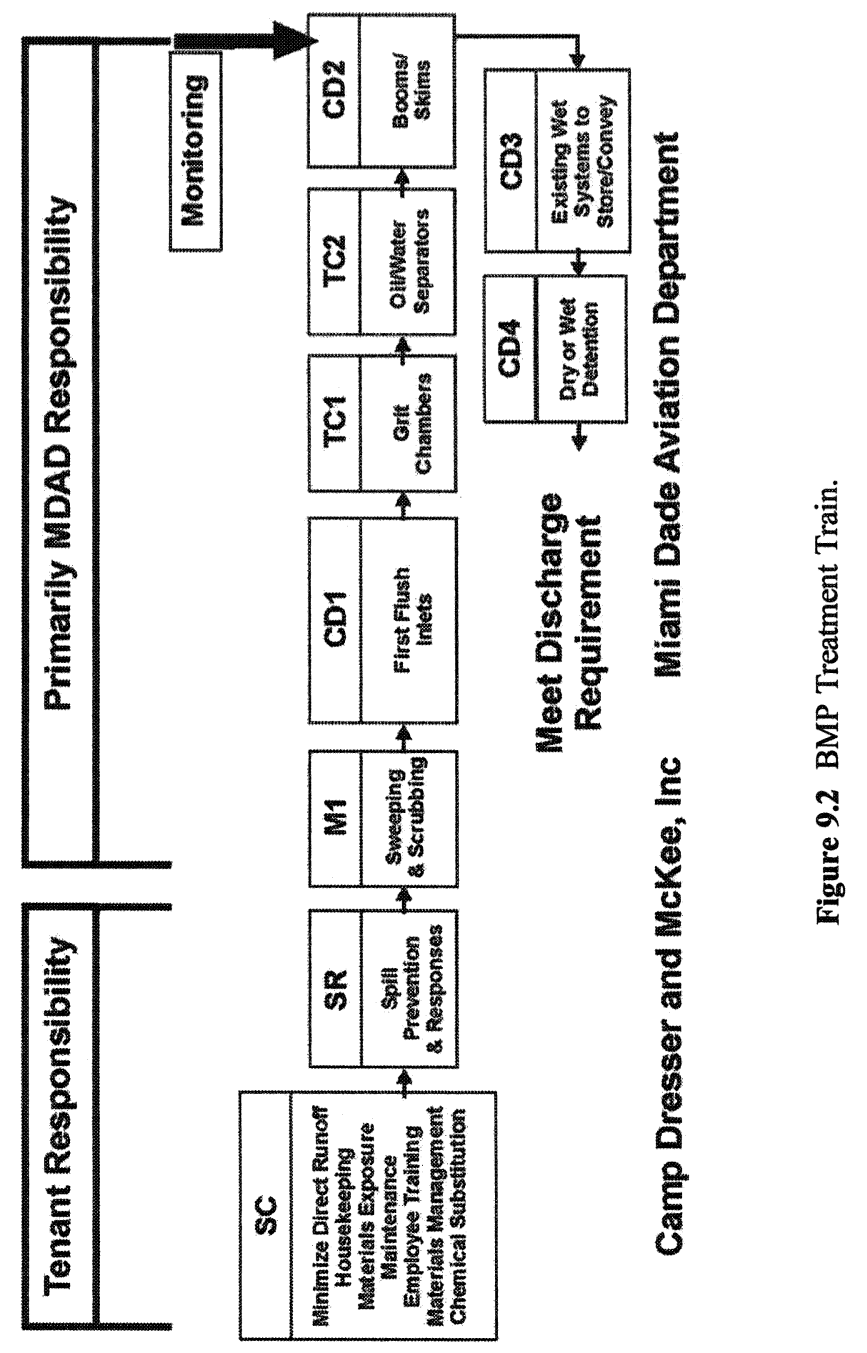




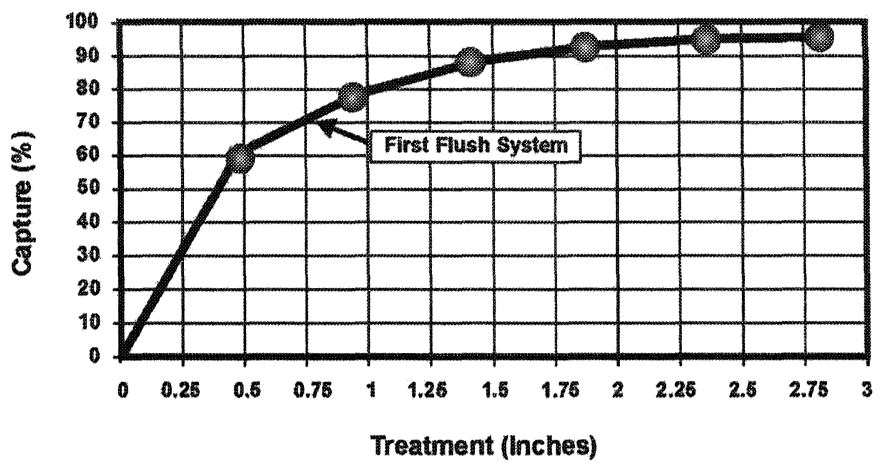

Figure 9.3 BMP Treatment Train, average annual rainfall volume capture curves.

\subsection{Monitoring Program}

A compliance-monitoring program was implemented by MDAD to meet the requirements of USEPA, SFWMD, and DERM. The water quality monitoring activities included the monitoring of onsite BMPs, internal site locations to determine relative load contributions by subwatershed, the five airport outfalls, and the receiving waters. This included the establishment of fixed grab sample locations and installation of automatic water quality monitoring sampling equipment and flow measuring equipment. The receiving waters include the Tamiami Canal and Miami River. These watercourses are tidal and have high

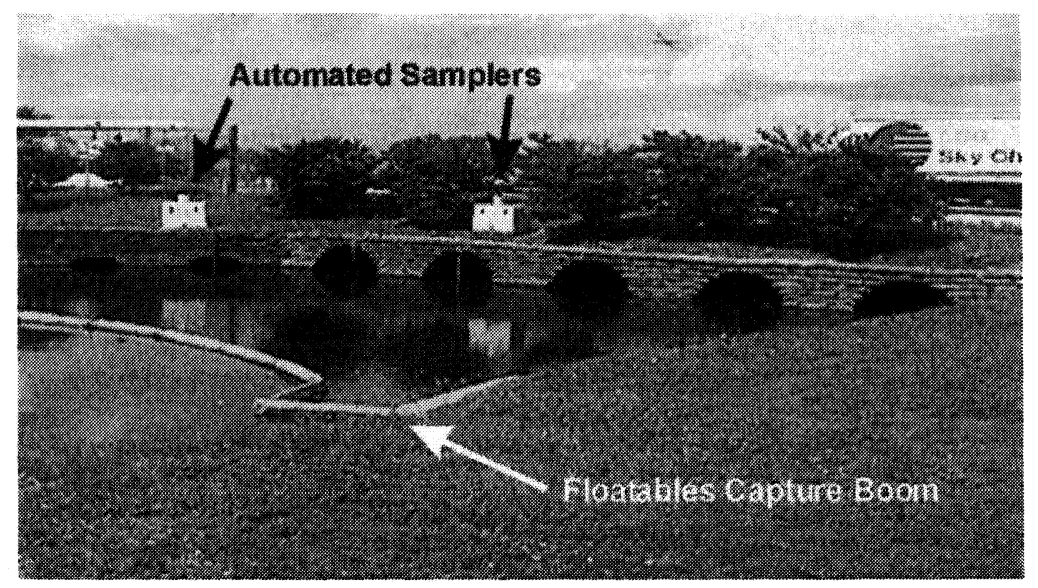

Figure 9.4 Strategic monitoring. 
conductivity and occasional low dissolved oxygen. It was important to document the airport's contribution in order to identify what MDAD could control by onsite activities. Figure 9.4 shows an in-system location for wet weather monitoring.

\subsection{Construction}

The construction included the retrofitting of existing stormwater facilities and new construction of stormwater management facilities; with emphasis on first flush diversion inlets, grit chambers, state of the art oil-water separators, and automated boom and skimmer devices downstream. The first flush inlets, which divert flows offline for treatment, are key components of this system. Note the twin peripheral troughs on the example inlet (Figure 9.5).

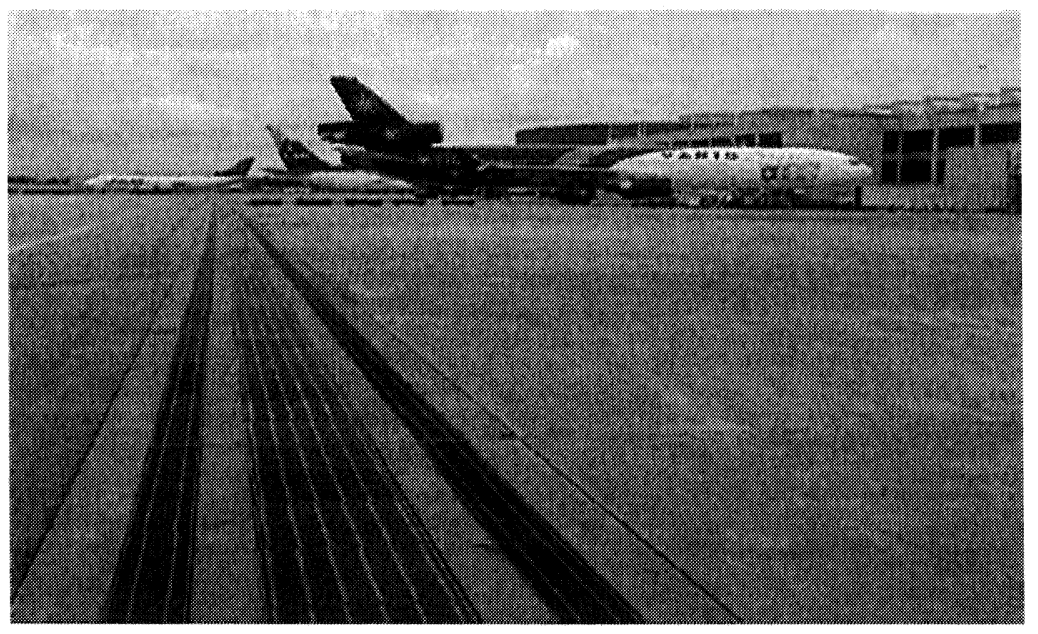

Figure 9.5 First flush diversion inlet.

The first flush of runoff is diverted offline to the grit chamber for suspended solids removal. The grit chamber (baffle box) schematic is shown in Figure 9.6.

The oil-water separators use inclined coalescent plates coupled with hydrophilic media to maximize oil removal for collection and offsite disposal (Figure 9.7). 


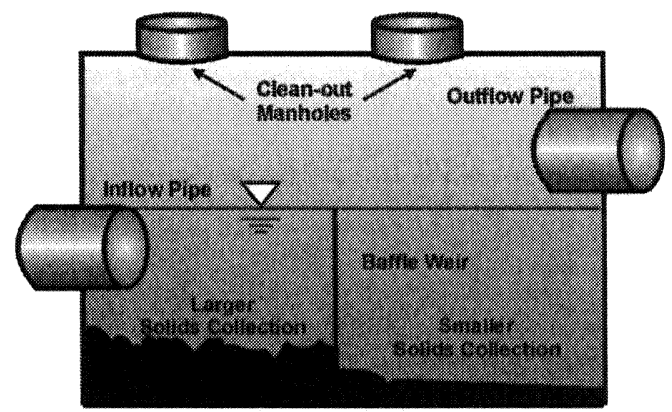

Figure 9.6 Grit chamber (baffle box) schematic.

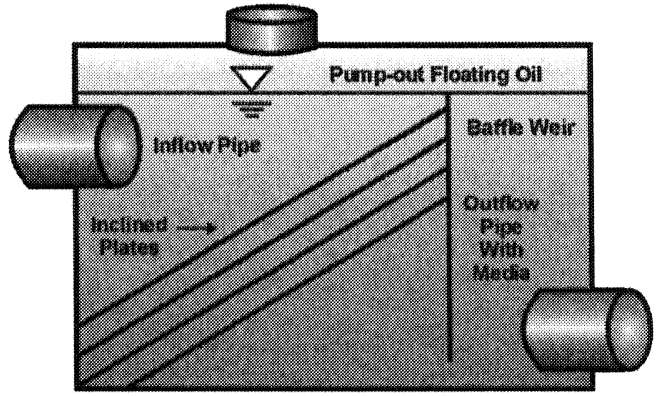

Figure 9.7 Oil-water separator schematic.

Flow is then recombined with the PSMS after treatment, and additional treatment is provided in the PSMS (large junction boxes, existing onsite canals, and booms). An example of the boom and skimmer system is shown in Figure 9.8. This angled orientation uses the in-system velocity of flow to "push" debris to the bank for skimming and removal.

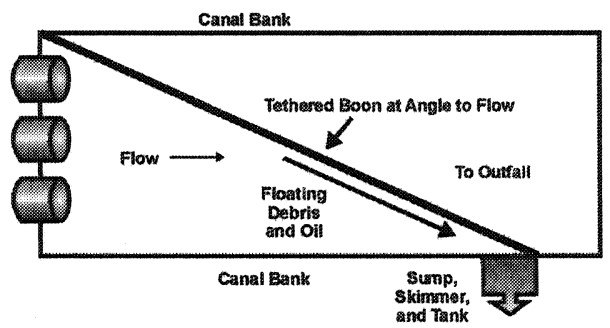

Figure 9.8 Boom and skimmer schematic, plan view. 
The 1994 SFWMD permit modification for the Terminal Area Watershed included a requirement to implement a supplemental water quality treatment system (supplementary to the BMP Treatment Train) by 1999. Accordingly, CDM assisted MDAD in the preparation of a Preliminary Design Report (CDM, 1995) which evaluated various alternatives, ranging from an industrial stormwater treatment facility (physical-chemical process) to conventional stormwater ponds offsite. This supplemental system will augment the improvements from the BMP Treatment Train, which has resulted in a noticeable improvement in the water quality at the airport, evidenced by the water quality testing results over the 5-y monitoring period from 1995 to 2000.

Over time, the improving water quality sampling results and flood control needs pointed to conventional ponds as more practicable and appropriate than an industrial type facility. However, efforts to negotiate the use of various offsite lands for conventional treatment have been elusive, suggesting the desirability instead of considering alternative onsite devices for supplemental water quality treatment in specific areas.

\subsection{Ongoing Activities}

MDAD is currently working on the implementation of the supplemental site specific BMPs in the Terminal Watershed to increase dissolved oxygen and further improve water quality of airport discharges. As part of this effort, the existing water quality data was reviewed to investigate the appropriate BMPs

for a given area. This examination included potential exceedances of parameter concentrations at the outfalls as well as the BMP removal efficiencies. The data indicate that State of Florida water quality standards are generally met and indicate good ranges of removal for various target parameters including BOD, TSS, metals, oil and grease, and some nutrients. Considerations for the additional proposed devices included:

- parameters of concern and BMP efficiencies,

- cost of the devices,

- space requirements for the devices,

- maintenance requirements of the devices, which include labor, operation, material disposal, and/or additional equipment requirements,

- ease and practicality of installation, and

- number of devices required which would affect price and the specific locations of devices. 
CDM used existing water quality data by area to determine the most appropriate location for the installation or implementation of such devices. The next step was to investigate BMP devices that will meet the water quality requirements. Recommendations were made to add aerators at two outfalls and additional in-pipe BMP components in six additional areas. These are currently under design.

\subsection{Program Costs}

To date, MDAD has implemented over US $\$ 179$ million of stormwater improvements to serve the US\$5.4 billion CIP. This has included the BMP Treatment Train components, manatee barriers, and extensive pipe retrofits as well as a 20 -acre ( $8 \mathrm{ha})$ dry detention pond with pump stations and control structures. System maintenance expenditures were US $\$ 2.725$ million over the 18 months it takes to complete one full "sweep" of the stormwater system.

In addition, MDAD is actively involved in the remediation of hazardous materials at over 80 sites for a total of US $\$ 137$ million. This has been carefully coordinated with the Stormwater Management Program to ensure that hazardous plumes are not disturbed or moved by changing groundwater gradients or by interception of stormwater facilities. Ongoing airport operations have also continued throughout the redevelopment process, including hosting the 1994 Conference of the Americas.

\subsection{Conclusions}

MDAD has proactively and successfully implemented a BMP Treatment Train to improve water quality in conjunction with ongoing capital improvements, while managing flood control onsite and offsite. This includes a series of activities to reduce nonpoint source pollutant load generation and to remove pollutants from the runoff prior to discharge. The BMP Treatment Train has been shown by water quality monitoring to cost-effectively treat runoff from the airport to meet federal, state, and local standards and permit requirements. Implementation has been coordinated with a US $\$ 5.4$ billion CIP to allow timely and appropriate retrofits to the system.

This approach has met the FAA requirements for land uses to reduce potential fog and bird hazards in order to protect passenger/aircraft safety balanced with environmental protection by compliance with the USEPA 
NPDES permit for stormwater, the SFWMD Environmental Resource Permit (ERP) requirements, FDEP requirements for groundwater cleanup (construction "in the wet"), and DERM stormwater permit requirements.

\section{References}

Camp Dresser and McKee, Inc. 1992, Miami International Airport Terminal Area Watershed Stormwater Master Plan.

Camp Dresser and McKee, Inc. 1995, Miami International Airport Terminal Area Watershed Preliminary Design Report Supplemental Water Quality Treatment System.

Federal Aviation Administration 1997, Advisory Circular Number 150/5200-33.

Florida Department of Environmental Protection (FDEP), Florida Land Development Manual, 1986.

Miami-Dade Department of Environmental Resource Management, Environmental Regulations Chapter 24.

South Florida Water Management District 1992, Permit Information Manual Volume IV.

US EPA 1994, National Pollutant Discharge Elimination System Permit for Miami International Airport. 